

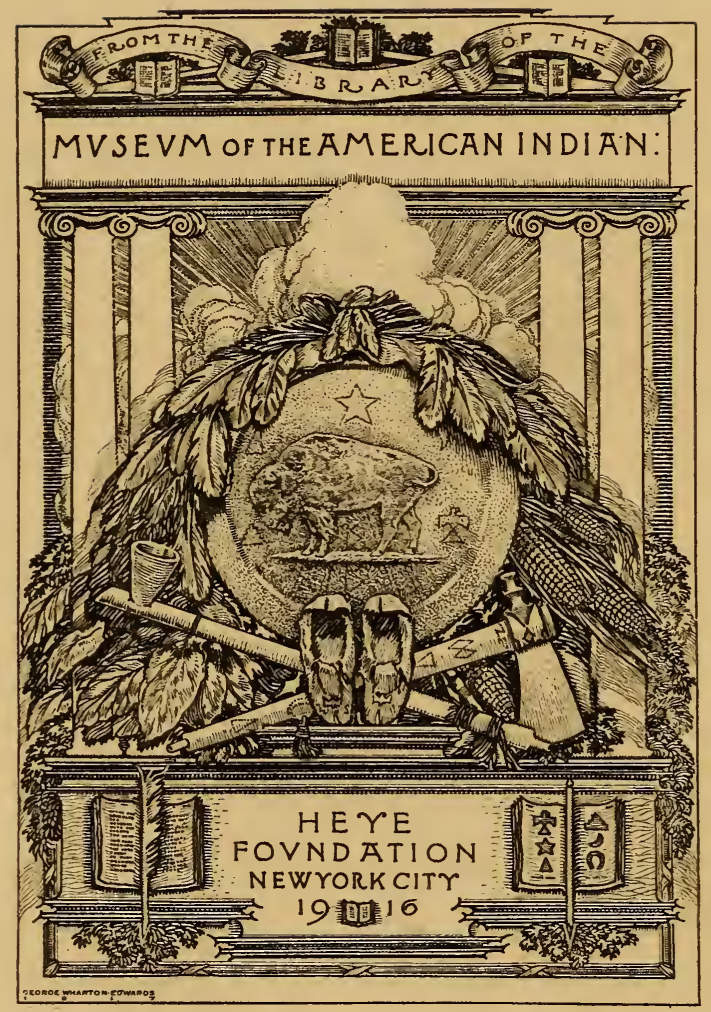


1075 

1. Walter Tewhes. 

CONTRIBUTIONS FROM THE HEYE MUSEUM

NUMBER 7

\section{PREHISTORIC OBJECTS FROM A SHELL-HEAP AT. ERIN BAY, TRINIDAD}

BY J. WALTER FEWKES

Reprinted from the American ANTHRopologist (N.s.), Vol. XVI, No. 2, April-June, I9r4

PRESS OF
THE NEW ERA PRINTING COMPANY LANCASTER, PA.

IOI4

id
SMITHSONIAN JUL 202000 LIBRARIES 


PREHISTORIC OBJECTS FROM A SHELL-HEAP AT ERIN BAY, TRINIDAD 


\section{PREHISTORIC OBJECTS FROM A SHELL-HEAP AT ERIN BAY, TRINIDAD}

\section{By J. WALTER FEWKES}

\section{INTRODUCTION}

T $N$ the winter of $1912-13$ the author visited the Lesser Antilles with a view of gathering data for a contemplated memoir on the aborigines of those islands. ${ }^{1}$ He visited the more important private collections of prehistoric objects, as well as those in public libraries and museums on the islands. Incidentally he carried on excavations, of a limited nature, at Banana bay, Balliceaux, where the Black Caribs of St Vincent had a settlement before they were deported to Ruatan on the coast of Honduras. Excavations believed to be important were made in a shell-heap in Trinidad, one of the largest and culturally most important of the Lesser Antilles. The present paper considers the more instructive results of the work last mentioned.

Trinidad is well adapted for the home of an aboriginal people. It has constant fresh water, an abundant supply of food, its mountains and plains being well stocked with animals, the sea affording an abundance of fish, mollusks, and crabs, and its soil yielding a large variety of edible roots and fruits. The island lies in full view of the coast of South America and was visible to the natives inhabiting the Orinoco delta. On its lee side the water is shallow, but landing can be made at many places in small craft. There are high hills in the interior, level savannahs along the coasts as well as inland, and streams of fresh water that open into brackish lagoons.

Early historical references to the Indians inhabiting Trinidad date from the discovery of the island by the great Genoese. As

1 This visit was made under the joint auspices of the Bureau of American Ethnology and the Heye Museum. The specimens collected are in the latter institution. 
Columbus on his third voyage, in I 498 , sailed with his companions along the shore of the newly discovered island which he had named after the Holy Trinity, writes Peter Martyr, "From their ships they could see that the country was inhabited and well cultivated; for they saw well-ordered gardens and shady orchards, while the sweet odours, exhaled by plants and trees bathed in the morning dew, reached their nostrils." Following the shore somewhat farther, Columbus "found a port sufficiently large to shelter his ships, though no river flowed into it." There was no sign of any habitation in the neighborhood of this harbor, but there were many tracks of animals similar to goats, and in fact the body of one of these animals was found. On the morrow "a canoe was seen in the distance carrying eighty men, all of whom were young, good looking, and lofty of stature. Besides their bows and arrows, they were armed with shields, which is not the custom among the other islanders. ${ }^{1}$ They wore their hair long, parted in the middle and plastered down quite in the Spanish fashion. Save for their loin-cloths of various colored cotton, they were entirely naked." Columbus naively declared that he followed in this voyage the parallel of Ethiopia, but recognized that the people he found in Trinidad were not Ethiopians, for the "Ethiopians are black and have curly, woolly hair, while these natives are on the contrary white [lighter in color?] and have long, straight blond hair."'2

According to Las Casas, who is said to have possessed accounts of the third voyage of the great Admiral which are now lost, the sailors of Columbus saw human foot-prints on the shore of Trinidad and discovered implements showing that the aborigines were fisherman. As Columbus skirted this coast he observed houses and cultivated fields "bien probada a labrada," indicating that

1 The Orinoco Indians had elaborate shields.-J. W. F.

${ }^{2}$ It is not improbable that in ancient times there was frequent communication between the inhabitants of the mainland of South America and Trinidad, a communication that was kept up until quite recently, for it was only a few years ago that canoe-loads of Indians were accustomed to land at Erin bay, at rare intervals, and make their way by an old Indian trail to the present city of San Fernando, via Siparia, through the original forests. These visits are now made primarily for tracle and are probably a survival of a custom quite common in prehistoric times. Well-marked "Indian trails" can still be followed through the forest depths. 
agriculture as well as fishing was practised by the natives. In the meager reference to the people given by Las Casas, he says incidentally that "they were lighter and better proportioned than those of the other Antilles, and wore their hair long like the women of Castile. They wore variegated cloth head-bands, and girdles on the loins. The men were armed with bows and arrows, and, unlike the inhabitants of the other Antilles, had [war] shields." 1 The identity of these people is not clear from this early account, but somewhat later they were referred to as Arawak.

Sir Robert Duddeley, in I595, made a journey through Trinidad and lodged in "Indian towns," finding the natives a fine-shaped and gentle ${ }^{2}$ (sic) people, naked and painted red.

Later, Sir Walter Raleigh enumerated the following "nations" or races in Trinidad: Yaios, Amecos (Arawak), Salvagay (Salivas), Nepoios, and Carinepagotos. At the end of the seventeenth century there were said to have been fifteen Indian towns in Trinidad, but the 2,032 aborigines recorded as inhabiting the island in $I 783$ had dwindled to $\mathrm{I}, 082$ ten years later. ${ }^{3}$

In some of the early historical references to Trinidad, all the natives are classed as Arawak. ${ }^{4}$ Thus Davies ${ }^{5}$ writes: "It was when the Captain was engaged for the war against the Arawages who inhabit Trinity [Trinidad] Island, and to that purpose he made extraordinary preparations." In other references to the Trinidad aborigines which might be quoted, the name Carib does not occur, and indeed there is no good evidence that there were Carib on the island, notwithstanding. several of the above-mentioned tribes are supposed by some authors to be divisions of "Caribs."

1 The Warrau, who lived on the mainland, have a large square shield called ha-ha, used in athletic sports. (See E. F. im Thurn, Among the Indians of Guiana, London, I883, p. 327.)

2 This is not characteristic of the Carib, according to ideas current then or in later times. It may be noticed, en passant, that there is no mention of Carib in the early accounts of the Indians in Trinidad seen by Columbus.

${ }^{3}$ On Bryan Edwards' map of the West Indies an "Indian town" appears on the east coast of Trinidad.

${ }^{4}$ The historical evidences all agree that the people of this island were an agricultural race allied in culture to Arawak.

${ }^{5}$ History of the Caribby Islands, I66I. 

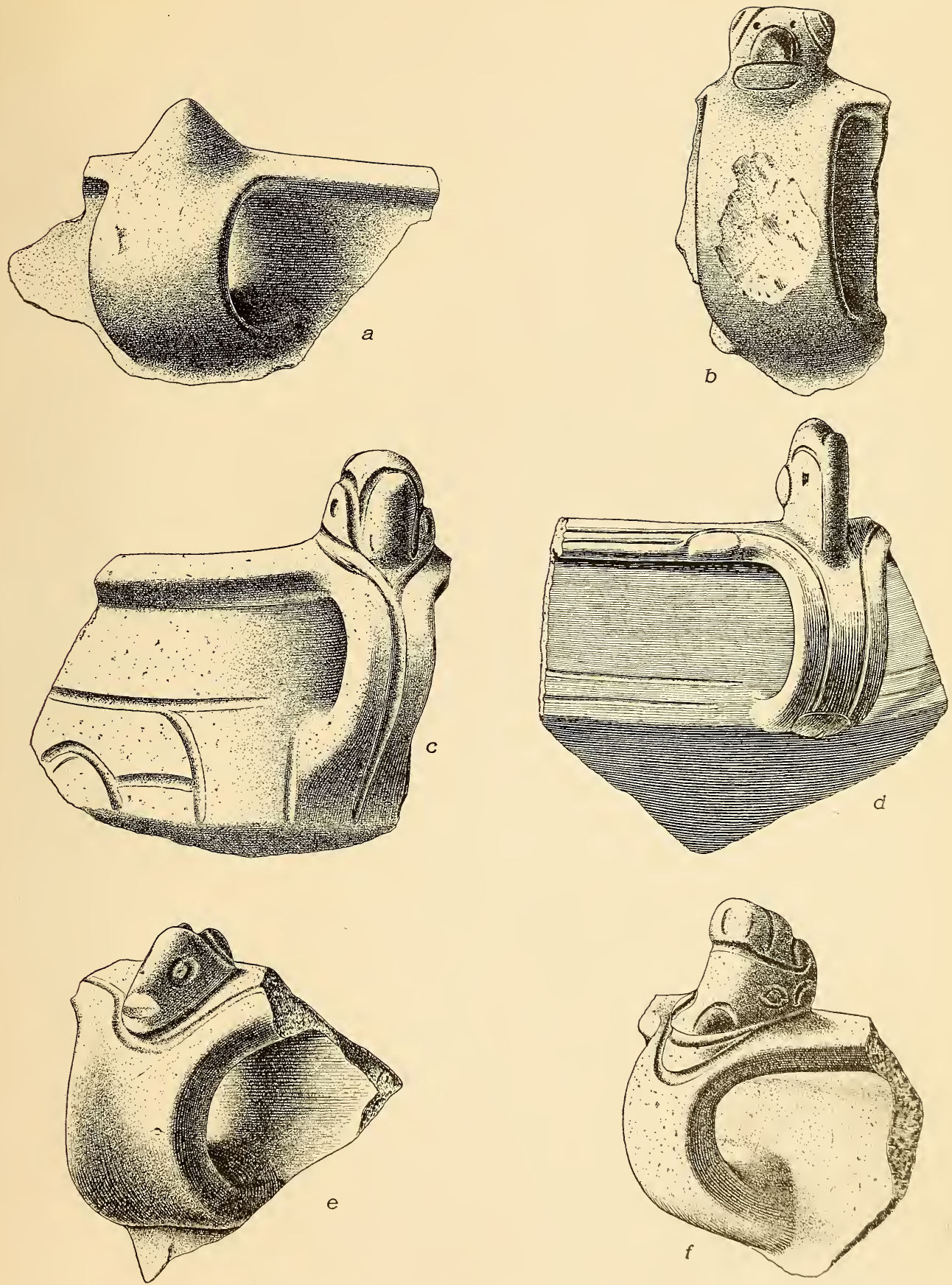

POTTERY CBJECTS FROM TRINIDAD

$a$. Bowl handle with conical projection. $b$. Bowl handle with head. $c, d$. Sactions of vessal with animal heads. $e, f$. Handles with animal hearls. 

The nearest approach to pure-blood aborigines of Trinidad live at Arima, in the middle of the island; but aboriginal features can still be found elsewhere among the inhabitants, although the author was unable to learn of a person who could speak any aboriginal language once spoken on the island, or that there were any Indians of pure blood remaining. There survive in Trinidad numerous Indian place-names, as Arima and Naparima; but while some of these suggest names existing in Porto Rico and St Vincent, they are as a rule dissimilar, indicating different languages. The prehistoric inhabitants of Trinidad were probably linguistically distinct from those of the other islands.

Additional knowledge of the culture of the aborigines of Trinidad can be acquired either by archeological research or through survivals in folklore, which are very common.

\section{ERIN BAY, TRINIDAD}

The small settlement at Erin bay consists of a few shops, two churches, and a number of dwellings along a well-built road that passes through the town to a warehouse on the shore. Small steamers anchor at intervals a few miles from the coast, but the best way to reach the settlement is by steamer from San Fernando to Cap de Ville and by carriage from the landing. It can also be visited from San Fernando by road, via Siparia. The only accommodations for remaining over night at Erin are at the Government House.

The present population consists almost wholly of blacks and East Indian coolies indentured to English planters or overseers, who own or manage the larger estates. The vernacular is a French patois of peculiar construction and incomprehensible to any but the inhabitants. The plantations are large and considerably scattered; they produce profitable crops, mainly cocoa and tropical fruits that are shipped to Port of Spain for export.

Not far from Erin there are remnants of the primeval forests in which game, monkeys, and tropical vegetation abound. The land is rich and productive, and the estates are prosperous. There are a few small kitchen-middens on the coast, not far from Erin, some 
of which will well repay excavation, but their isolation is a practical difficulty unless complete and systematic work be done. ${ }^{1}$

There are several shell-mounds on the eastern coast of Trinidad which show fragments of pottery and other rejecta, and several heaps on the southern shore that are superficially composed of shells. In the so-called shell-heaps at San José, the shells are few and inconspicuous, but in a midden at Point Mayaro, which covers a fairly large area, many characteristic potsherds may still be found on the surface. As a rule these shell-heaps are not far from the shore, but in several instances they lie inland. ${ }^{2}$

Fragments of pottery from this region sent to the author by Mr Dearle of Port of Spain differ from those of Erin bay, but apparently were made by people in the same stage of culture. There is a small collection from this region in the Heye Museum, obtained after this report was completed, which contains a number of highly instructive heads and other fragments. This pottery is colored white and purple-red, whereas that from the shell-heap at Erin bay is painted bright red, although the color is often worn, showing gray beneath.

\section{TCIP-T CIP SHELL-HEAP}

The largest shell-heap in Trinidad, locally known as Tcip-tcip hill, situated at Erin, a short distance from the shore, covers several acres and forms a considerable elevation. Upon this mound are constructed the government buildings, the police station, and the warden's office. The author obtained from the assistant warden, Mr John Menzies, ${ }^{3}$ permission to make excavations in that part of the shell-heap situated on Crown land, but was obliged to suspend

1 Trinidad has never been regarded as a remunerative field for archeological investigation. The first results of the author's efforts in the island were not very promising, but after some discouragement, excavations of a shell-heap at Erin bay, in the Cedros district, yielded important data bearing on the former culture of the aborigines in this part of the island.

${ }^{2}$ Efforts to find evidences that man inhabited the numerous caves in Trinidad, or used them for burial purposes, have not been rewarded with success, although many caves, especially those near Pedro Martin's basin, were examined.

3 The author is very grateful to Mr Menzies for his aid, and takes this opportunity to thank him for his many kindnesses while at Erin bay. He is likewise indebted to Mr Dearle, of Port of Spain, for voluntary aid in the excavations. 

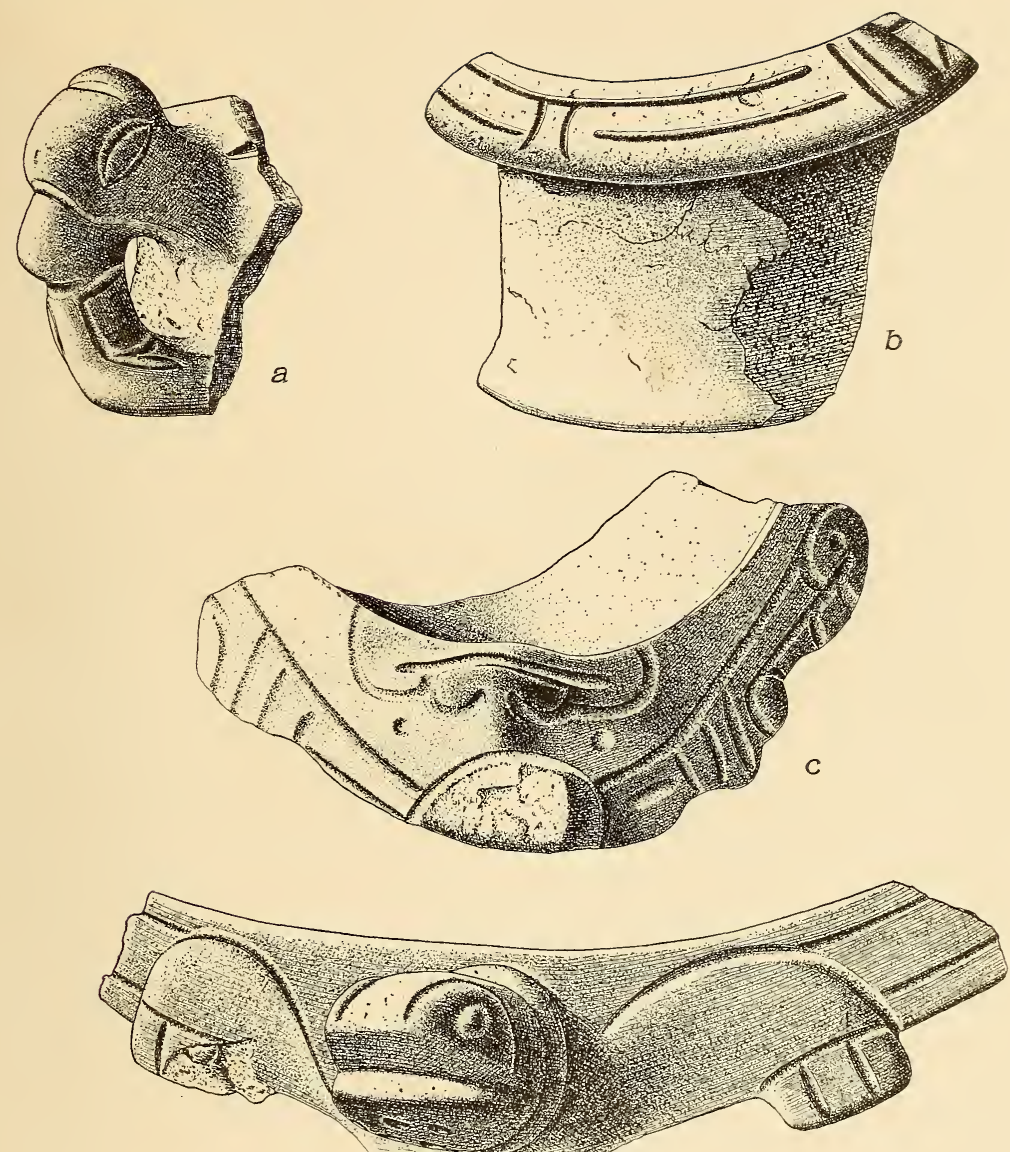

d

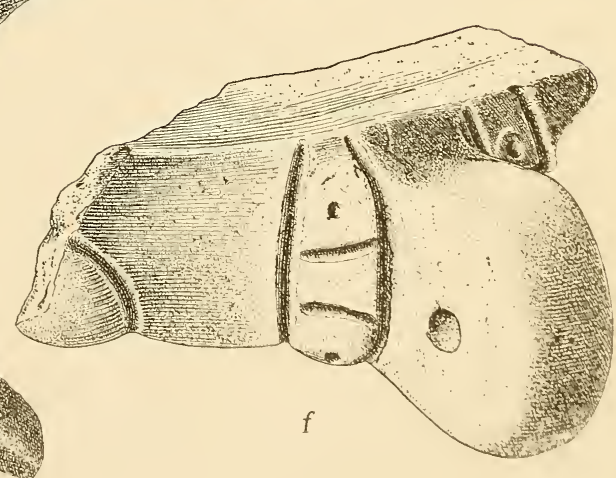

POTTERY OBJECTS FROM TRINIDAD

$a$. Handle with modified head. $b$. Section of rim of vessel. c. Rim of eftigy bowl. d. Rim with heal mullipers. $e$. Rim with head. $f$. Flattened disk with circular hamble, 

work on the private land adjoining, as it could not be thoroughly explored without injury to the property. The specimens, although limited in quantity, are the most numerous known, and give a fair idea of the nature of the contents of a typical Trinidad shell-heap.

Tcip-tcip hill was first described by Mr Collens, whose excavations therein were rewarded with several fine specimens, now on exhibition in the Victoria Institute at Port of Spain. These objects are figured by Collens in his Handbook of Trinidad, and are also illustrated by the present author in his Aborigines of Porto Rico. ${ }^{1}$

Some limited excavations were also made at Tcip-tcip hill by the Reverend Thomas Huckerby, of San Fernando, several years after Collens finished his work, but only a few fragments of pottery, now in the Heye Museum, were obtained.

The extent of the Tcip-tcip mound could not be determined, as it extends far into the cocoa plantation under a dense tropical growth. Its surface, except where cleared by the Government for the erection of buildings, was covered with vegetation. Some distance from the hill, where a ceiba tree had fallen, the roots showed a considerable deposit of shells, indicating that the extent of the heap was great and furnishing a clue for continued excavations.

The shells in the mound at Erin are in layers alternating with vegetable mold, ashes, and soil, forming a sticky mass ${ }^{2}$ that clings tenaciously to the specimens and almost conceals their identity. The terra-cotta heads, when dug out of the earth, were completely coated with mud which had to be removed by washing, and by so doing some of the red pigment which covered them disappeared. As the ceramic objects had been painted after they were fired, the color is not permanent, and the length of time they had been in the ground caused it to come off even more readily.

As mentioned, a vertical section of the mound exposed alternating layers of shells and ashes, mingled in some cases with humus and with frequent fragments of charred wood. Sometimes the strata were composed entirely of shells, but their thickness was not uniform, especially at the periphery of the mound. Over the entire

${ }^{1}$ Twenty-fifth Annual Report, Bureau of American Ethnology, pl. 1xxxv.

${ }^{2}$ During the author's work in Trinidad it rained almost every day.

AM. ANTH., N. S., I6-I4 
surface of the mound there was a dense growth of tropical vegetation, with clearings at intervals for cocoa and plantains. The fallen trunks of palms, live shrubs, and trees formed an almost impenetrable jungle extending into the neighboring forests where the ground had not been cleared. On the sea-side the mound is only a short distance from the shore and is separated from the bay by a lagoon inclosed by a narrow strip of land. Near by is a spring from which the shipmates of Columbus obtained drinking water in 1498 .

In their general character the objects found in the Tcip-tcip mound are not unlike those occurring in other West Indian middens, although they differ in special features. As is usually the case, the majority of the specimens are fragments of pottery, which are among the most instructive objects by which culture areas can be defined. These will be considered first.

\section{PotTery}

Comparatively little has been published on the pottery of the Lesser Antilles, although specimens of whole jars and innumerable fragments are found in various museums and private collections. The Heye Museum is the richest in the world in these objects. The potter's art was practised by aboriginal people from Trinidad to Cuba and the Bahamas, but while there is general similarity in the product, there are very marked specific differences.

The several beautiful specimens of pottery in the Victoria Institute at Port of Spain, Trinidad, two of which, through the kindness of the officers of that institution, were photographed, have been reproduced by the author, ${ }^{1}$ who has quoted the description in the appendix in Collens's Guide to Trinidad, here reprinted as it contains practically all that has been published on the archeology of Trinidad.

"The discovery of some interesting Indian relics at Erin during the past month [May, I888] is, although I had brought my work to an end, of sufficient importance to demand a brief notice. On the occasion of a recent visit of His Excellency, Mr. W. Robinson and suite to the southern quarter of the island, the Hon. H. Fowler, who was one of the party, observed a mound of shells. Dis-

${ }^{1}$ Aborigines of Porto Rico, Twenty-fifth Annual Report, Bureau of American Eihnology, pl. lxxxv. 

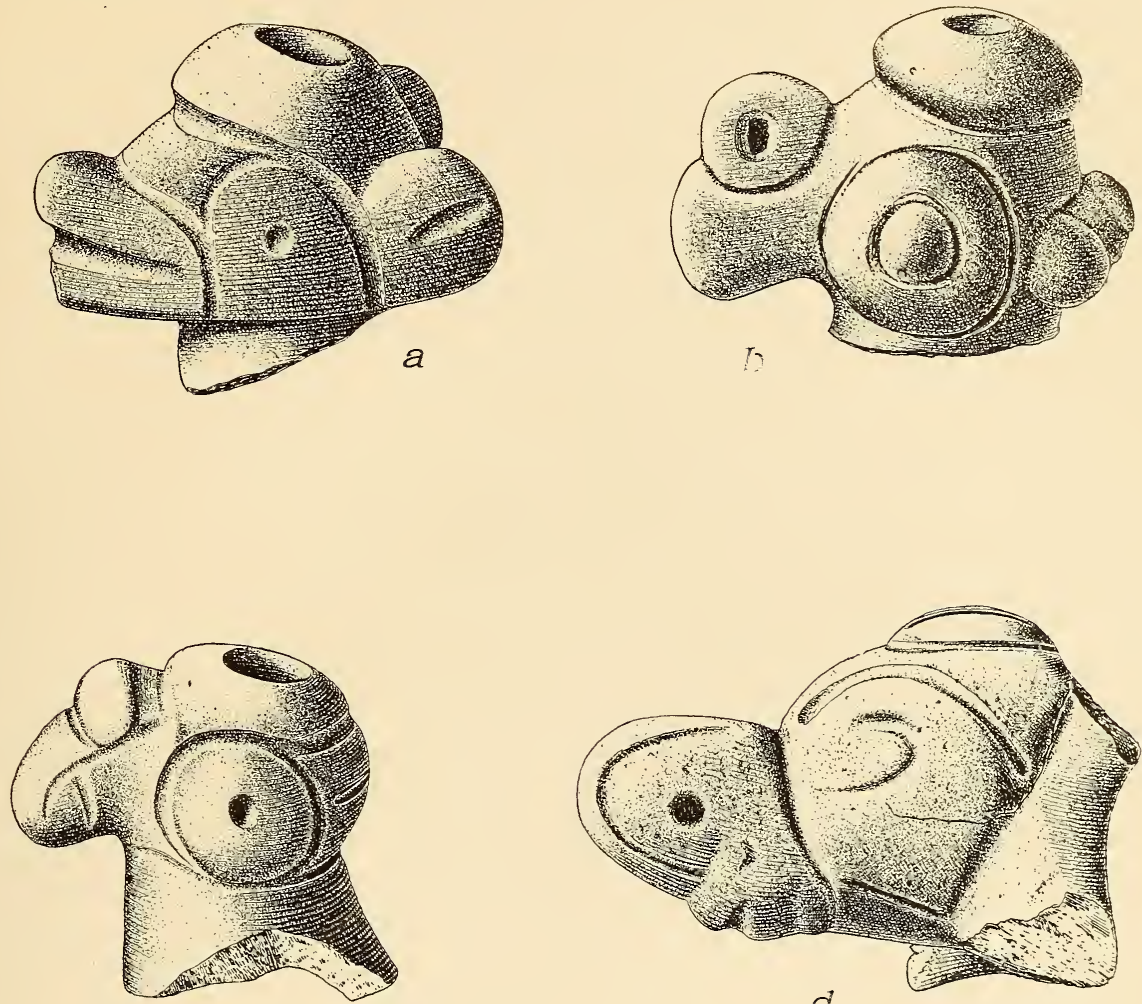

C
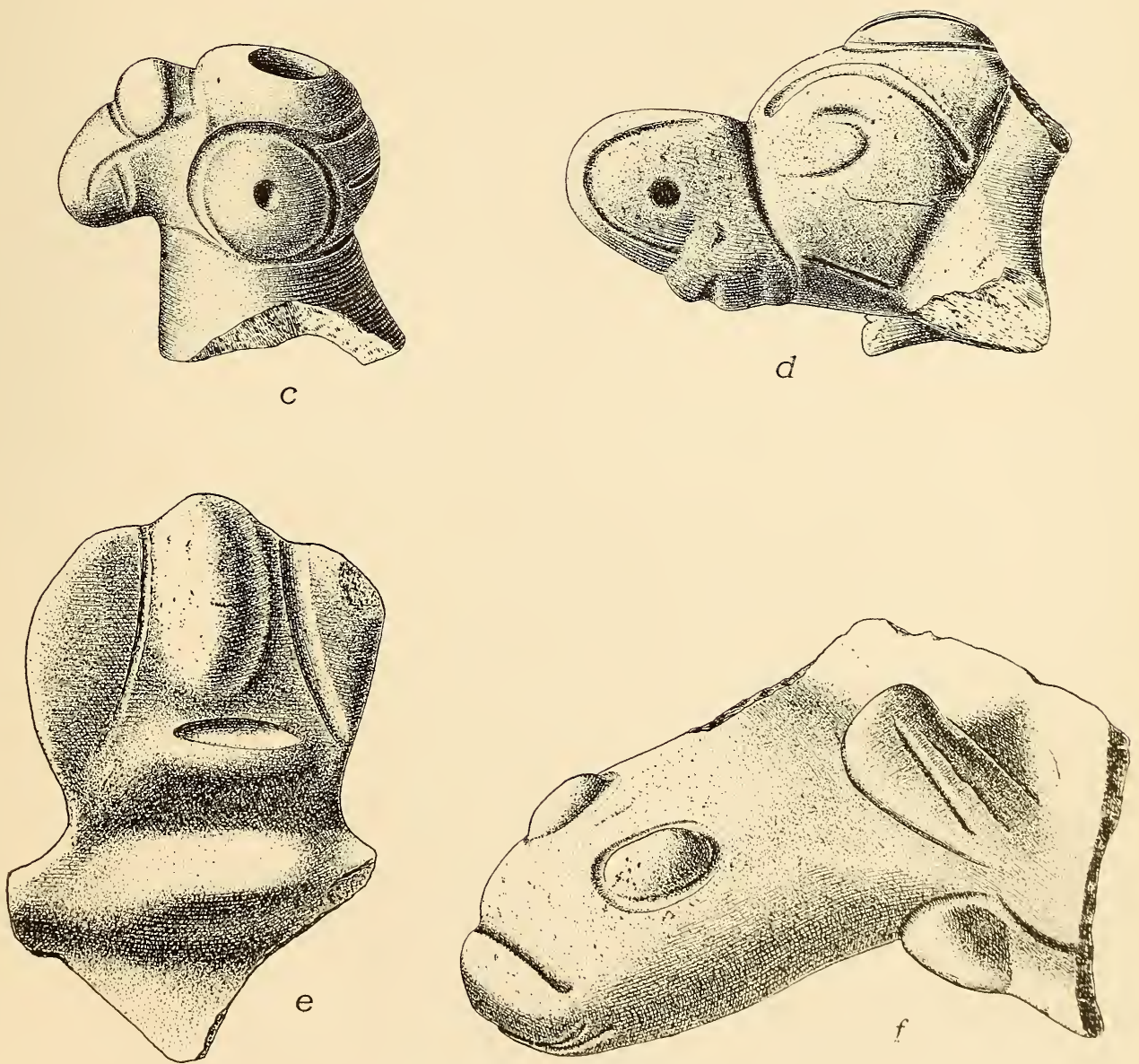

POTTERY OBJECTS FROM TRINIDAD

$a, b, c$. Bottle heads. $d$. Head. $e$. Conventionalized head. $f$. Elongated head. 

mounting, a closer inspection revealed some pieces of rude pottery, and subsequent excavations by Mr. A. Newsam, the Warden, led to the unearthing of some capital specimens, indicating beyond a doubt this had been the centre, at some period more or less remote, of an Indian settlement. The pottery is of two kinds, glazed ${ }^{1}$ and unglazed, the latter dating back to a time anterior to the discovery of the New World, for the art of glazing was unknown to the early Indians, nor is it likely that they became acquainted with it after the Spanish occupation."

\section{The following specimens are figured by Collens:}

FIG. I. A hollow stone, smooth in the concave part, forming a rude mortar. The Indians used a hard, smooth pestle for pounding their seeds and grains.

FIGs. 2, 3, 4. Heads of animals in burnt clay, more or less grotesquely shaped. The eyes and mouth are exaggerated, a few, broad, bold lines serving to bring out the most striking features. In fig. 4 the head of the monkey is fantastically crowned. All these are probably deities or ornamented attachments of earthen vessels.

FIG. 5. A well shaped squirrel. Perhaps a toy whistle.

FIG. 6. An earthen bowl in fine preservation, about the size of an ordinary vegetable dish. With the lid, which is unfortunately missing, there would doubtless be a good representation of a turtle; as it is the head and tail are clearly, and the limbs somewhat clumsily shown."

The best entire vessel found by the author in his excavations at the Erin bay midden is the shapely brown vase shown in figure 64 . This receptacle was buried two and half feet beneath the surface, in a thick layer composed wholly of shells. Its association and situation show no indication that it was deposited with care, and it could not have been a mortuary vessel, as no bones were found near by: it appeared rather to have been abandoned or dropped by its

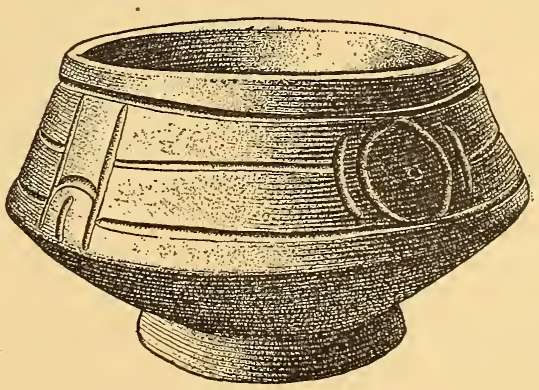

Fig. 64.-Bowl with ring at base and incised decoration.

owner where it was found. The shape of this vase is an uncommon one in prehistoric West Indian pottery. In form it is

1 The author regrets that he cannot support Mr Collens's statement that glazed pottery occurs in the Tcip-tcip mound.-J. W. F. 
enlarged equatorially, and tapers above to a recurved lip, which, as is rarely the case in West Indian earthenware, is without handles or lugs, and below, in which region the exterior is slightly convex, to the base. Decoration in the form of incised lines appears on the surface of the upper area, but the under portion is smooth and without ornamentation. This decoration consists mainly of parallel grooves alternating with crescents, and circles with central dots. The walls of the vessel are thinner than is usual in West Indian pottery, and the surface is little worn. An exceptional feature of this receptacle is the base, which consists of a circular stand, thus rendering stability to the vessel. Similar bases of other specimens, being much more substantial than the bodies, are frequently preserved entire while the remainder has disappeared. This form of base is of common occurrence in fragments also from St Vincent and Grenada, but is rare in Porto Rico.

Several bowls had been so long in the moist soil of which the Tcip-tcip mound is composed that they crumbled into fragments when an effort was made to lift them from their matrix. Although

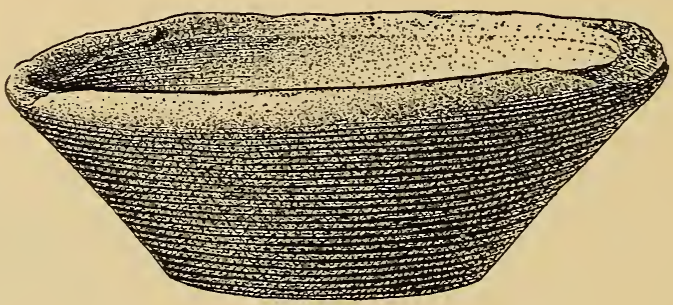

FIG. 65.-Bowl with flat kase.

the forms of these bowls vary somewhat, several resemble that shown in figure 65 , which may have been used for condiments or for pigment. ${ }^{1}$ The walls of this vessel are thick, with smooth undecorated surface; its bottom is flat. The rim shows two opposite imperfections that may indicate the position of heads which served as handles. ${ }^{2}$

${ }^{1}$ Many fragments of red and green pigment were found in the mound. The majority of the vessels here described are of gray or bright red ware.

${ }^{2}$ After pottery objects were taken from the mound they hardened considerably, but the handles of this vessel may have been broken from the rim previous to its recovery. 


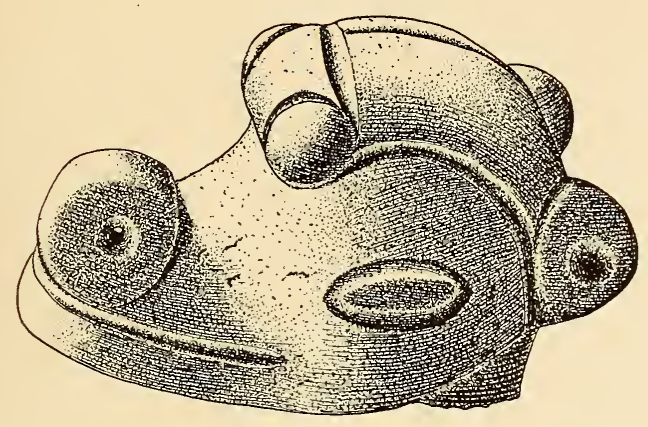

a
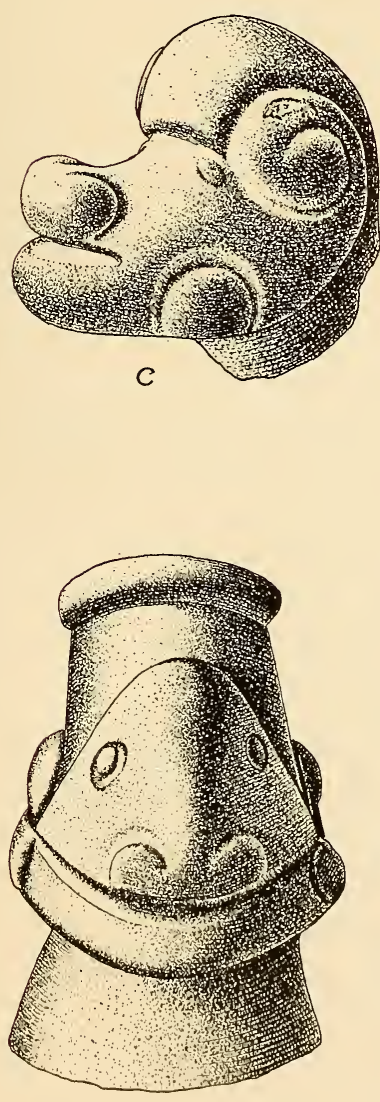

e
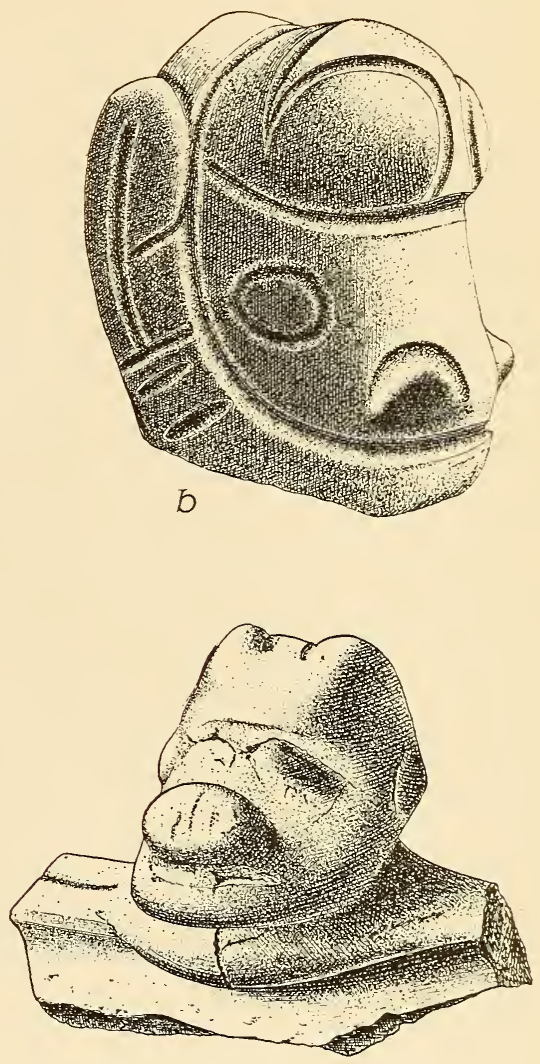

d

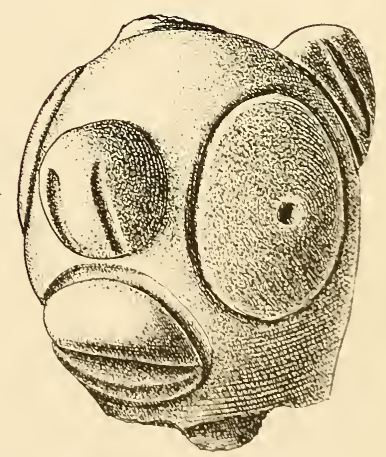

POTTERY OBJECTS FROM TRINIDAD

$a, b, c, f$. Heads. $d$. Head with broken rim, $e$. Head of bottle. 

Figure 66 represents a small rude pottery rest, of spool-shape, with flat base, very thick walls, smooth undecorated surface, and somewhat flaring rim. Its size suggests that it was once used as a toy or as a ceremonial vessel, but it was more likely designed as a support for a bowl. Some beautiful pottery rests from St Vincent are in the Heye collection, several of which, in a fragmentary condition, were obtained by the author at Balliceaux. The most elaborate of these measures about six inches in height, is perforated on the sides, and has a face in high relief.

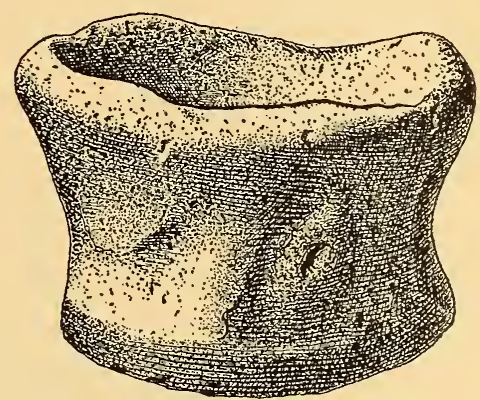

Fig. 66.-Pottery rest. This object will be fully described in a subsequent report.

The rectangular clay box shown in figure 67 has thick walls, a flat bottom, and squatty legs continuous with the sides. Its longer sides bear incised $S$ figures surrounded on three sides by a straight furrow. The narrow sides of the vessel are ornamented with incised crescents also partly framed with straight lines. From

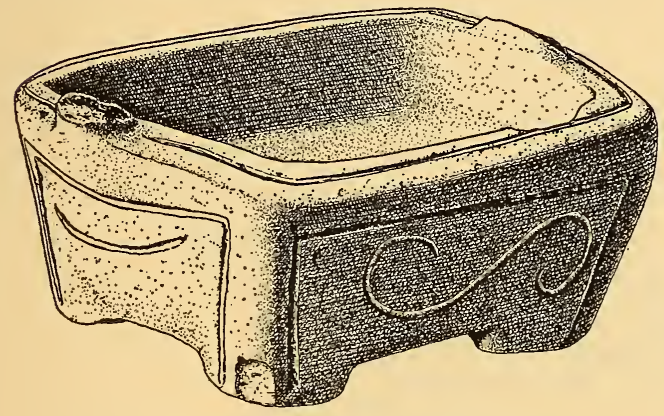

FiG. 67.-Rectangular vessel. the broken places at the two opposite shorter sides of the rim it would seem that the vessel had been provided with handles, probably in the form of heads, but it is also possible that a head may have been attached to one side and a tail opposite, thus producing an effigy vessel. Rectangular receptacles of this kind are rare in collections of West Indian pottery, a fact which imparts special interest to this example.

The object shown in figure 68 is a fragment of a bowl, shaped like a turtle, with head and tail, and the left legs drawn up to the 
remaining side of the body. This interesting specimen is almost identical with the unbroken turtle effigy vase figured by Collens, to which reference has already been made. Although nearly half

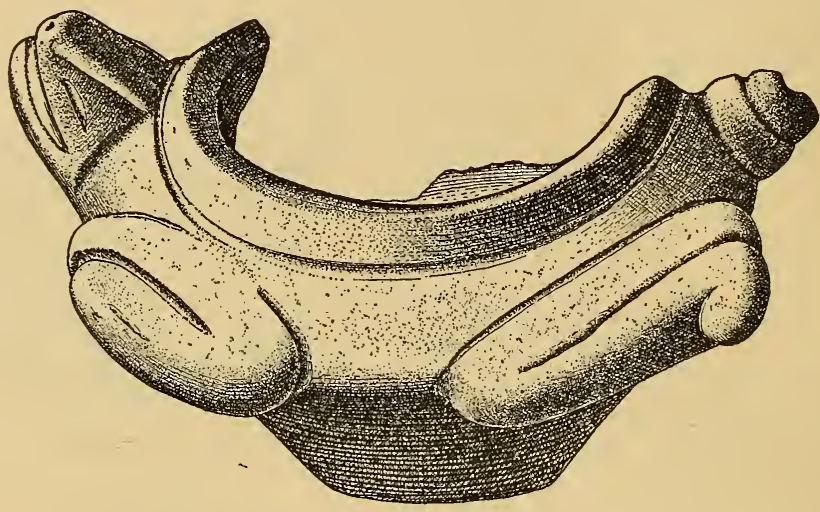

FIG. 68:-Fragment of a turtle effigy bowl.

of this specimen is absent, enough remains to enable a determination of its form and of the general character of the relief decoration, which was no doubt identical on the two sides. ${ }^{1}$ The head, which is not attached directly to the rim of the vessel but to the upper side, is rather long, with blunt snout, and mouth extending backward;

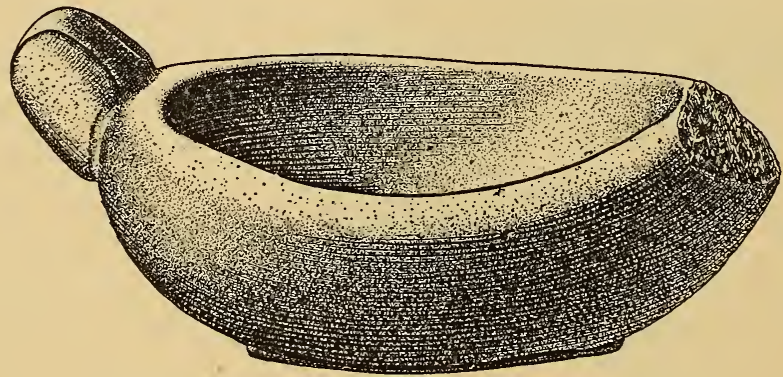

FIG. 69.-Effigy bowl possibly representing a turtle.

the nostrils are indicated by pits, the eyes by slits. The tail consists of two buttons separated by grooves, and the fore and hind

${ }^{1}$ Unlike the clay turtle figured by Collens, this specimen has no raised rim about the base. We know from historical sources that the turtle played an important part in Antillean mythology, which accounts for its frequent appearance on ceramic and other objects. 

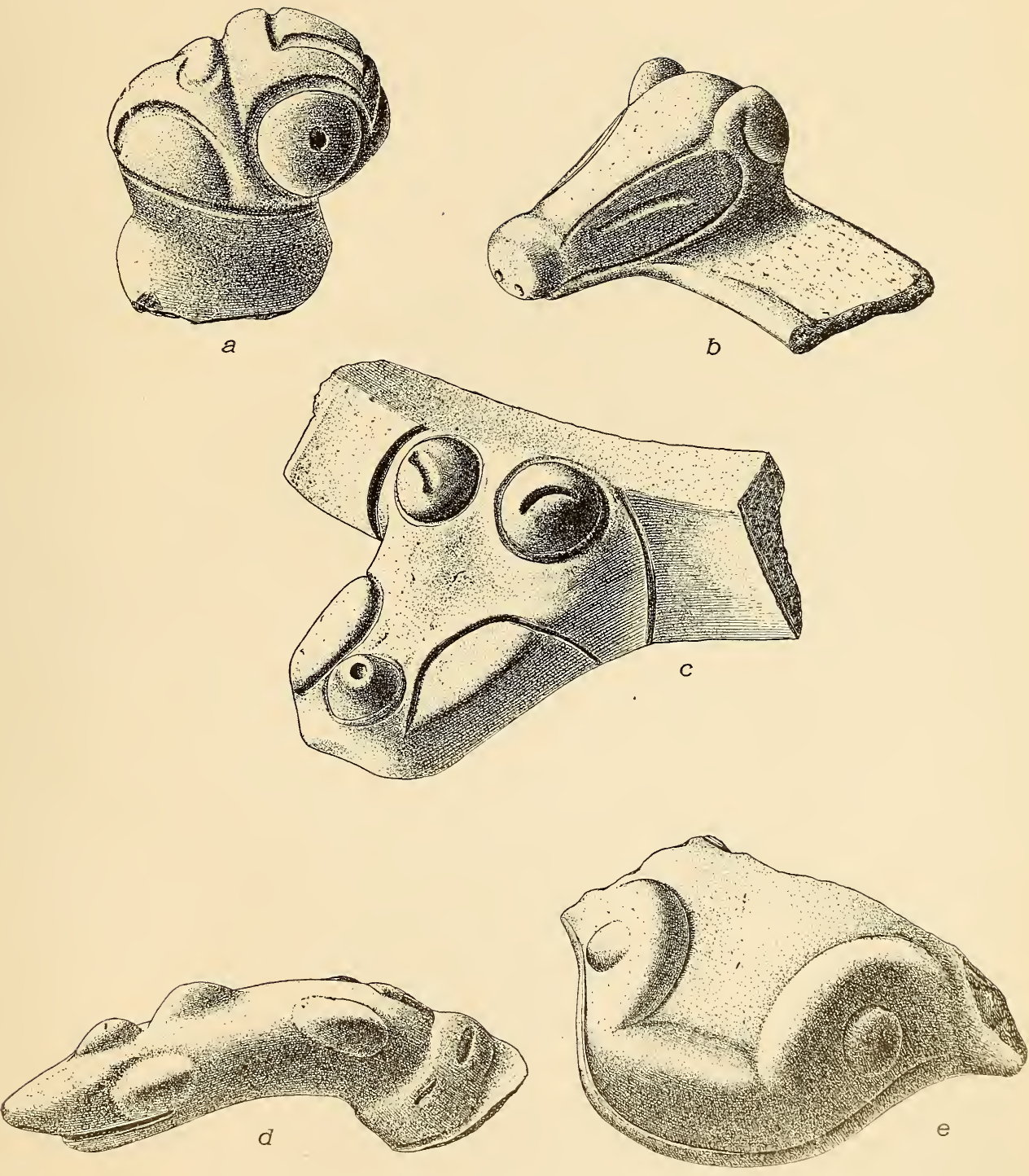

POTTERY OBJECTS FROM TRINIDAD

$a, b$. Heads. $c$. Head on section of rim. $d$. Head and body of shark. $c$. Flattened head. 

legs, with no indication of flippers, are modeled close to the body. Like many Antillean earthenware vessels, the walls are thick and the rim not decorated.

The vessel shown in figure 69 is also supposed to be a turtle effigy, an almost featureless head being attached to the rim. Opposite the head the rim is broken, indicating where there may have been formerly an appendage representing the tail. This object fortunately is one of the few whole specimens in the collection.

In sharp contrast with the thick-walled, coarse bowl last mentioned, is a fragmentary vessel (fig. 70) which may be regarded as one of the finest and most elaborately decorated specimens found at Erin bay. This beautiful example represents the highest type of incised decoration of which the Antillean potter was capable. It shows the base and practically a quadrant

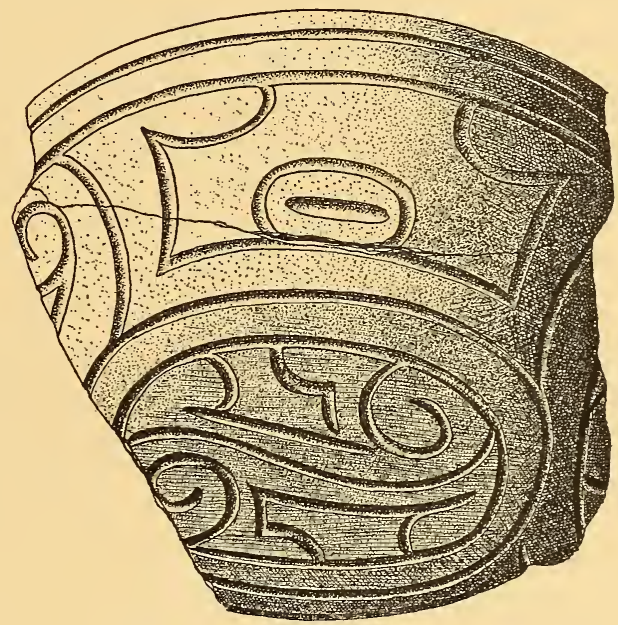

FIG. 70.-Decoration on food towl. of the lateral decoration of the bowl, which was probably repeated on the missing side.

In addition to the specimens of entire pottery above described, many fragments, some of which represent characteristic forms, were excavated from the Erin shell-heap. The best of these are sections of rims and handles, which, being less fragile, are more readily preserved. Their chief features will now be considered.

\section{Handles of Vessels}

Considerable variation occurs in the form of the handles of earthenware vessels, several of which are still associated with portions of the side or rim, while others show how the handle was 
attached at both extremities. Some of the handles are mere knobs or bosses, other examples are in the form of elaborate heads, the various modifications of which recall the pottery heads of Porto Rico and Santo Domingo.

The handles of bowls shown in the accompanying illustrations (pl. XIV-XIX) are broken from their attachments; sometimes they are very simple in form, but more commonly they represent heads which vary more or less in shape. The specimen (pl. XIV, a) which has a fragment of the bowl attached is one of the simplest forms, loop-shaped with a conical projection near the rim. The handle is broad, with ample space for the fingers. In some specimens the handles are even simpler, as they are without the conical elevation, while the upper end, instead of being attached to the rim, rises from the side of the bowl. In other examples the handle takes the form of a lug or knob.

In plate $\mathrm{xIV}, b$, instead of a conical knob, the handle consists of a simple head in which the eyes, nose, and mouth are crudely indicated, as in other West Indian vessels.

Plate XIV, $c$, shows a specimen in which the head surmounting the handle is modeled in greater detail, and a sufficient part of the body of the bowl remains to show the incised ornamentation of the exterior surface as well as of the handle. Incised lines unite at the throat and continue down the middle of the handle throughout its length.

The figure of the handle illustrated in plate XIV, $d$, is similar to that of plate XIV, $c$, but the two incised lines ornamenting it continue along the rim of the bowl and end above an oval elevation evidently representing the body of the animal. The slender head of the animal projects upward; the eyes are small, and incised crook-shaped lines extend along the head and partly surround the eyes. The equatorial girt of this vessel is somewhat larger than the circumference of the rim and is decorated with two incised parallel lines.

Another variation in form of effigy handle is shown in plate $\mathrm{XIV}, e$, the head represented in this case having a somewhat pointed snout, oval eyes surrounded by circular grooves, an open mouth, 
and projections separated by grooves on the head. This is more massive than the handles before described; it is not incised, and its breadth at the middle is somewhat less than at the point of attachment to the body of the vessel.

One of the most elaborate heads ornamenting a handle partly free from the body of the vessel is shown in plate XIV, $f$. This handle, like the preceding, is thick and broad. When placed with the rim of the vessel uppermost, the two grooves may be identified as lips, the crescents above them as nostrils, and the ring on the side as an eye. If, however, the figure is turned in such manner that the rim is vertical, the eyes and what was identified as the forehead become the snout with nostrils and mouth.

The handle shown in plate $\mathrm{XV}, a$, instead of being broad is small and rounded; it is decorated with incised lines, and the effigy portion is larger than the handle proper. The head is protuberant and the eyes lenticular. Although the other features of the head are considerably distorted, it would appear that the handle in this specimen extends from the top of the head instead of from the neck, thereby turning the mouth uppermost, as in the last example.

In the sections of the rims of vessels next to be described no handles are present. Plate $\mathrm{xv}, b$, represents a rim ornamented with two incised, horizontal, parallel furrows, alternating with vertical grooves. This rim is broad and flaring, with rounded margins, imparting a convex surface to this portion of the bowl, which has a straight body and a flat base.

The incised ornamentation on the example shown in plate $\mathrm{XV}, c$, is more elaborate than the last. In this case the rim is quite broad, somewhat pointed, and covered with furrows, indicating an elaborate figure which unfortunately cannot be wholly determined on account of its incompleteness.

Plate $\mathrm{xv}, d$, exhibits a well-modeled rim probably representing a turtle with open mouth and rounded eyes. The pits under the lower jaw are uncommon, but like other features are suggestive of a turtle's head. The two appendages at the side evidently represent flippers.

The well-modeled head indicated in plate $\mathrm{xV}, e$, is attached to 
a section of the rim, but placed lengthwise instead of vertically as in other specimens. The snout is elongated, while the mouth extends far backward; the eyes are indicated by pits, and a round projection separated by grooves appears on the forehead.

The degree of conventionalization in these specimens is sometimes very great, as in plate $\mathrm{xv}, f$, where practically all resemblance to a head is lost. Here we have a disk attached by one margin to the rim of a bowl, which is ornamented with a rude incised design. A handle distantly related to the last is illustrated in plate XVI, $a$.

It often happens that the walls of the orifice of a flask-shaped bottle are modified into a perforated clay head, ${ }^{1}$ as in the specimens shown in plate XVI, $a, b, c$.

Plate XvI, $b, c, d, e$, show varying forms of effigy heads which served as handles of vessels. All of them have well developed nostrils, eyes, and other facial features. The presence of nostrils differentiates these heads from many others and affords a hint, although obscure, as to the identity of the animal designed to be represented. We find similar nostrils in certain three-pointed stone idols from Porto Rico, which we have other good reasons to identify as reptiles, hence the conclusion is fairly logical that these heads were intended to represent similar creatures.

The two projections on top of the head and the form of the eyes and nose of the effigy shown in plate xvI, $f$, are exceptional. The crescentic mouth is suggestive of the same organ in certain unde-, termined Porto Rican stone idols of three-pointed form.

A remarkably well modeled reptilian head is shown in plate XvII, $a$. Its great elongation distinguishes it from the head shown in plate XVII, $b$, which is almost spherical and has the organs represented by incised lines rather than in relief. The same general tendency to rounded formis is exhibited in plate XvII, $c, d, e$, but in these the nose is notably exaggerated.

The head, and especially the position and form of the nose, of the handle shown in plate xvII, $f$, remind one of pottery from the Grenada region, a specimen of which is figured in the author's

${ }_{1}$ This is the first example of a head from a prehistoric flask-like vessel from Trinidad or the Lesser Antilles, although common in Hayti and Santo Domingo. 

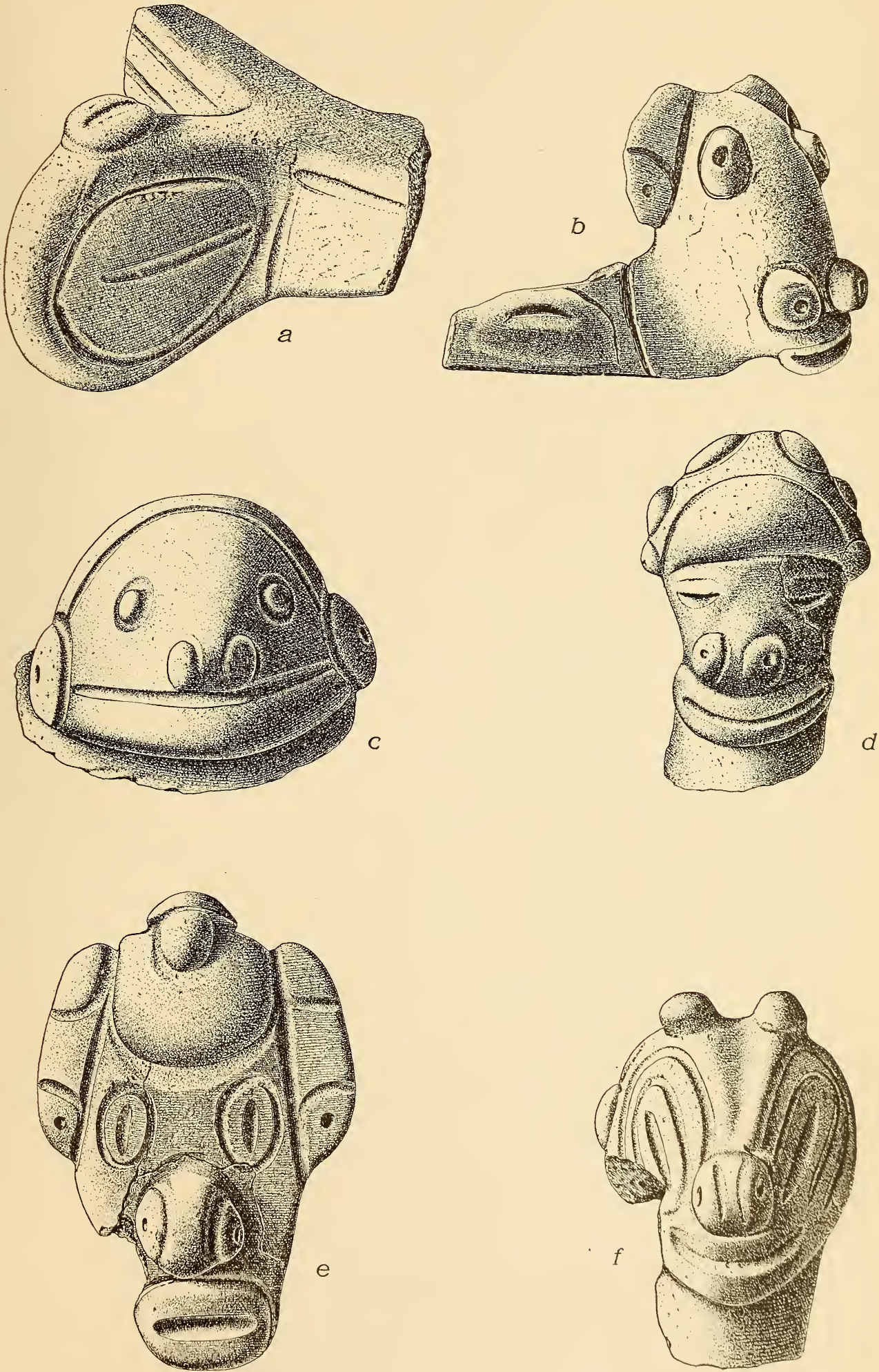

POTTERY OBJECTS FHOM TRINIDAD $a$. Round knob of vessel, $b-f$. Heads. 

report on the Aborigines of Porto Rico. ${ }^{1}$ In this instance eyes, nose, and mouth are indicated by hemispherical protuberances; the nostrils are represented by parallel slits, the eyes by pits in the middle of a circular disk, and the lips by a transverse furrow in a circular boss. A somewhat similar method of indicating these parts is shown in plate XVIII, $a$, while in $b$ the form of the head reminds one of a peccary, or wild hog. The mode of attachment to the rim of the vessel is quite apparent in this instance.

The unpaired nostril of the effigy shown in plate XviII, $c$ is indicated by a single pit in the summit of a conical projection; the eyes are prominent and contain crescentic slits. This head, as shown by a fragment of the rim still attached, projected farther beyond the bowl than is usually the case. The flat form of the head suggests an alligator, but it was evidently designed to represent a mythological conception rather than a realistic animal.

If superficial likenesses of conventionalized figures are regarded as reliable for identification, plate XvIII, $d$, might well be considered to represent a shark's head, for the position of the mouth in this specimen is well below the snout, which tapers above uniformly to its end. There is no doubt that the protuberances above the mouth were intended to represent eyes, while those near the rim of the vessel may have been designed for fins or other organs. No representations of nostrils or ears are apparent in plate XvIII, $e$, but the broad flat head has two eyes and a well developed mouth. The break at the point of attachment shows that it was a handle of a vessel.

The heads illustrated in plate XIX, $c, d, e$, cannot, by reason of their highly conventionalized character, be readily assigned to any of the forms above considered. There remains a considerable number of other pottery heads obtained at the Erin Bay midden, some of which are too greatly mutilated for identification.

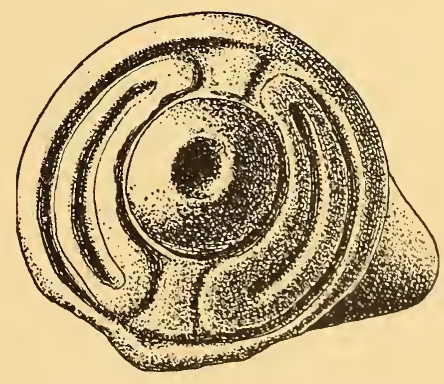

FIG. 7I.-Pottery stamp.

\footnotetext{
${ }^{1}$ Op. cit., pl. Ixxxiv.
} 
Figure 7I illustrates a clay stamp, one of a class of objects not uncommon in the Lesser Antilles. The face of this specimen is circular, with an incised design, and was probably used either for decorating pottery or in a manner similar to the clay cylinders elsewhere described. ${ }^{1}$ These stamps are often elaborate. Some of those lately obtained by $\mathrm{Mr}$ de Booy from Santo Domingo bear images on their surfaces and rattle when shaken.

\section{Stone Implements}

Stone implements from the Erin Bay midden consist of celts, axes, chisels, pecking-stones, mortars, pestles, and other forms. A number of almond-shaped celts, like Porto Rican petaloids, were collected in Trinidad. The most interesting axe is flat, with notches cut at opposite edges, as shown in figure 72 .

There is general similarity in the forms of the mortars found in the West Indies, but the pestles vary in different islands. In the

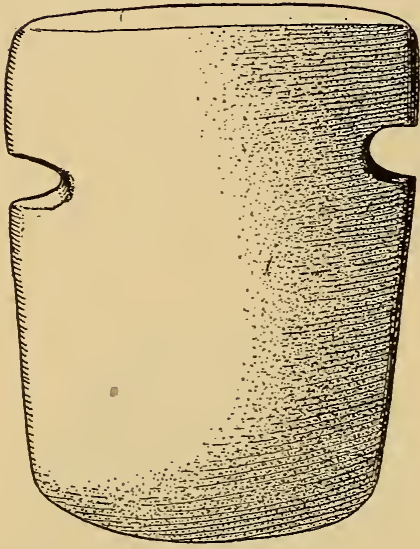

FIG. 72.-Notched axe.

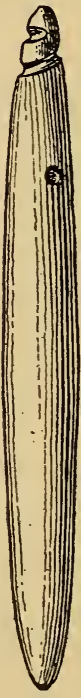

FIG. 73.-Jadeite pendant.

Santo Domingo-Porto Rico area pestles commonly have handles decorated with animal heads or even with entire animals, but in the

${ }_{1}$ Aborigines of Porto Rico, pl. 1xxxvi, a. 
St Kitts region they are simple unornamented cones, pointed at one end, circular or oval at the opposite end, but with no differentiation of base, handle, or head. The Guadeloupe and St Vincent pestles are of the same general character as those from St Kitts, which are identical with those found in Trinidad.

There are several stones in the collection from the Erin shell-heap that were evidently used for pecking other stones or for pounding pigments or bruising roots. They are elongate, sometimes angular, with shallow pits on two or all four faces which served to facilitate handling by providing convenient places for the thumb and forefinger. Circular stone disks, probably used as grinders, were likewise found.

A small finely polished pendant (fig. 73) made of jadeite, perforated at one end, was found buried deeply among the shells in the Erin Bay midden. In finish this beautiful specimen recalls certain finely polished green petaloids collected in Porto Rico and other islands. The stone of which these objects are made does not occur in the West Indies, a fact indicating that the pendant, as well as the celts, was brought from the mainland, probably from South America.

\section{Bone Objects}

Considering their occurrence in soil saturated with moisture, it is remarkable that bone objects were preserved in the Erin Bay mound, but many unworked animal bones and a few bone implements were exposed in the course of the excavations. One of the latter is from an unidentified animal, and its flattened form resembles a spatula used in pottery making. Among other bone implements may be mentioned a tube of uniform diameter, supposed to be an ornament, cut off at both ends and having a slit extending along two-thirds of its length.

\section{Овjects of Wood}

A fine black finger-ring, similar to the rings made and worn by the natives in several islands of the West Indies, was found deep in the shell-heap. It is made from a seed of the gougou palm. An angular fragment of lignite of irregular form, with an artificial groove encircling it, was found in one of the deepest excavations. 
Comparison of Prehistoric Objects from Trinidad with Those FROM OTHER ISLANDS

As is generally the case in archeological studies, pottery, from its greater durability and variety in form, is one of the most reliable types of artifacts for the study of prehistoric culture areas in the West Indies. The Erin Bay shell-heap shares with the middens of other islands a predominance of earthenware with effigy forms and relief decoration, and the incised ornamentation of pottery vessels from this mound are strictly Antillean. When we compare these specimens with those from Porto Rico, we notice certain specialized features which are distinctive. In geometric designs the incised lines do not end in an enlargement, nor are their extremities accompanied by pits as is almost always true of pottery from Santo Domingo and Porto Rico. Comparatively few elongated heads of reptiles are found on pottery from Porto Rico, but such forms are common from the shell-heap at Erin bay. The heads from Porto Rico are mainly grotesquely human in form. As a rule the rims of the earthenware vessels from Porto Rico have approximately the same thickness as the vessels themselves, whereas in Trinidad they are often enlarged, or turned back, and are commonly ornamented with figures as in the pottery from Grenada and St Vincent.

While it has been necessary to make comparisons mainly from fragments, it is believed that the number of characteristic forms of pottery figures from this and from more northerly islands are sufficient to separate the two and to lead to the belief that the pottery from Trinidad is most closely allied to that of the Grenada area, as would be naturally suspected, and that it is only distantly related to that of the Greater Antilles. ${ }^{1}$

While the evidence is not decisive, it appears from the material available that the Trinidad pottery is nearer that of South America than to any of the northern islands of the West Indies. This fact may be explained by the situation of Trinidad, which lies within sight of South America, a fact that led to an interchange of cultures and peoples of the two localities.

1 The author has many drawings of St Kitts pottery which shows still greater difference in form and ornamentation. 
The nearest point in South America where excavations of shellheaps have been made is the Pomeroon district, ${ }^{1}$ British Guiana, whence we have a few specimens of pottery. None of these are so well made as those from the Erin shell-mound, and there are other indications that the ceramic art had reached a higher development in the islands than on the adjacent mainland.

Regarding the Pomeroon shell-heaps, im Thurn reached the following conclusions: (I) "That they were not made by resident inhabitants of the country, but by strangers; (2) that these strangers came from the sea, and not from farther inland, and (3) that these strangers were certain island Caribs, who afterward took tribal form in Guiana as the so-called Caribisi, or, as I have called them, true Caribs."

Attention has been called at the beginning of this paper to the fact that the Trinidad aborigines are not spoken of as Carib, and the archeological objects show no likeness to the work of this people, but rather to that of the Arawak, who were the great potters of the Orinoco.

The well-made pottery of Erin bay suggests an agricultural population rather than the nomadic Carib people, and the form of certain flat clay platters, or griddles, is not unlike those used by the Arawak in the preparation of meal for cassava cakes. The aborigines who made these objects were in a stage of culture similar to that of a people of the West Indies before the coming of the Carib in prehistoric times. Pottery making is more strictly a characteristic of meal eaters, and as the South American Arawak were wellknown potters, we cannot go far afield if we ascribe the pottery from Trinidad to a kindred people. The nearest South American people to whom we would look for their kindred are the Guaranos, or Warrau, some of whom still inhabit the delta of the Orinoco, only a few miles across the Gulf of Paria, an inland sheet of water which separates Trinidad from the continent.

Although im Thurn identifies the builders of the Pomeroon shell-mounds as insular Carib, he gives some weight to the theory

${ }^{1}$ E. F. im Thurn, Among the Indians of Guiana, London, I883. See also Rev. W. H. Brett, The Indian Tribes of Guiana, Their Customs and Habits, London, I868. 
that they were Warrau, which theory, however, he does not discuss and apparently does not accept. It seems to the author that the pottery found in the Tcip-tcip mounds indicates a culture higher than that of the Carib, and more advanced as art products than any thus far collected from the Warrau. He regards it as a localized or autochthonous development originally of South American origin, but belonging to the same great prehistoric insular culture found in the Antilles from South America to the Bahamas and Cuba. This culture had been submerged by the Carib in some of the smaller islands, but persisted into the historic epoch in the larger islands which Carib could not conquer.

The conclusion reached from a comparison of the objects from the Erin Bay midden is that while there is a general likeness in pottery from all the islands of the West Indies, there are special ceramic culture areas in different islands. It is also believed that the Carib had no extensive settlement in Trinidad, and that they came to the other islands long after agricultural people had developed on them, or were renegades from some of the islands where the uncertainty of crops drove them to become marauders on others.

Bureau of American Ethyology

Washington, D. C. 



